\title{
Study on screening of canola varieties with high light use efficiency and evaluation of selecting indices
}

\author{
Rui Wang ${ }^{1, *}$, Wenli Peng ${ }^{1}$, Liyong $\mathrm{Hu}^{2}$ and Weixian $\mathrm{Wu}^{1}$ \\ 1 Tongren University, Tongren, Guizhou 554300, PR China \\ 2 College of Plant Science and Technology, Huazhong Agricultural University, Wuhan, Hubei 430070, PR China
}

Received 2 June 2020 - Accepted 24 July 2020

\begin{abstract}
High light use efficiency is an important factor for yield improvement during the growing season for winter canola. This study explored the evaluation method of high light use efficiency during the whole growth period in order to screen high light use coefficient of crop genotypes in canola producing areas of Southwest China. The pot experiment was conducted with sixty canola cultivars which had already been planted in the crops planting areas of the middle and upper reaches of Yangtze River. The plant height, root neck diameter, number of pods per main inflorescence, pods per plant, dry weight of shoots, seed weight per plant, pericarp weight per plant, ratio of pericarps to seeds weight per plant, seeds number per pod and 1000grain weight were investigated under the shading treatment of reducing the incoming solar light by $20 \%$. The high light use coefficient of canola cultivars was evaluated comprehensively by principal component analysis, membership function, cluster analysis and stepwise regression analysis. With these analyses, the original twelve indices related to light use efficiency could be synthesized into the four independent indices which represented $86.4 \%$ of all the investigated information of canola with high photosynthetic efficiency. Sixty varieties were classified into three groups by cluster analysis, and ZS12, GYZ6, FY792, RHY6, CZY3 and ZYZ19 displayed higher light use efficiency; such 18 varieties as XDZY9, XY1, YY50 and so on, were medium light efficient ones; and the rest 36 varieties such as LY9, ZYZ781, SG127 and so on, fell to the relatively lower light use efficiency categories. The comprehensive evaluation in this study had screened such four indicators as the stem dry weight per plant, the pod number per plant, the seed number per pod and the 1000-seed weight, which could be regarded as identification indicators for high light use efficiency of canola.
\end{abstract}

Keywords: canola / high light use efficiency / principal component analysis / subordinate function / comprehensive evaluation

\begin{abstract}
Résumé - Étude de criblage de variétés de colza à haute efficacité d'utilisation de la lumière et évaluation des indices de sélection. L'efficacité de l'utilisation de la lumière est un facteur important pour l'amélioration du rendement durant la période de croissance du colza d'hiver. Cette étude a exploré un moyen d'évaluer la performance de l'utilisation de la lumière pendant toute la période de croissance afin de sélectionner les génotypes de cultures à haut coefficient d'utilisation de la lumière dans les régions productrices de canola du Sud-Ouest de la Chine. L'expérience en pot a été menée avec soixante variétés de colza cultivées dans les zones de culture des cours moyen et supérieur du fleuve Yangtze. La hauteur de la plante, le diamètre du collet des racines, le nombre de siliques sur l'inflorescence principale et par plante, le poids sec des siliques, le poids des graines par plante, le poids du péricarpe par plante, le rapport entre le péricarpe et le poids des graines par plante, le nombre de graines par silique et le poids de 1000 grains ont été étudiés dans le contexte expérimental d'un ombrage visant à réduire de $20 \%$ la lumière solaire entrante. Le coefficient élevé d'utilisation de la lumière des cultivars de canola a été évalué de manière exhaustive par analyse en composantes principales, fonction d'appartenance, partitionnement des données (cluster) et analyse de régression par étapes. Ces différentes analyses ont permis de synthétiser les douze indices originaux liés à l'efficacité de l'utilisation de la lumière en quatre indices indépendants qui expliquent $86,4 \%$ de toutes les informations étudiées sur le colza à haute efficacité photosynthétique. Soixante variétés
\end{abstract}

*Correspondence: ngywr@gztrc.edu.cn 
ont été classées en trois groupes par partitionnement des données : les variétés ZS12, GYZ6, FY792, RHY6, CZY3 et ZYZ19 ont montré une plus grande efficacité d'utilisation de la lumière; 18 variétés comme XDZY9, XY1, YY50, étaient d'une efficacité lumineuse moyenne; et les 36 autres variétés comme LY9, ZYZ781, SG127, etc. sont tombées dans les catégories d'efficacité lumineuse relativement plus faibles. L'évaluation complète a retenu quatre indicateurs : le nombre de siliques sur l'inflorescence principale, le nombre de siliques par plante, le nombre de graines par silique et le poids de 1000 grains, qui peuvent être considérés comme des indicateurs d'identification de plants de colza dotés d'une efficacité élevée d'utilisation de la lumière.

Mots clés : colza / haute efficacité d'utilisation de la lumière / analyse en composantes principales / fonction d'appartenance / évaluation complète

\section{Introduction}

Light use efficiency (LUE) is the amount of biomass per unit of light intercepted by the crop, and LUE is a useful term to relate yield to canopy photosynthesis (Singh et al., 2018; Danso et al., 2020). Some researchers have suggested that variation in LUE could attribute to physical factors of the crop environment or intrinsic characteristics of canola (Velicka et al., 2012; Brunel-Muguet et al., 2013; Kuai et al., 2016; Xu et al., 2019). The efficiency of conversion of solar radiation energy into biomass by the canola is usually represented by a calculated value which is the conversion efficiency of intercepted radiation or light use efficiency (Singh et al., 2018).

The low photosynthetic efficiency, the low and unstable yield of canola varieties have become the important factors limiting the development of the canola industry. Therefore, it is an urgent problem for breeders and cultivators to find a suitable way to improve the yield of canola. At present, the actual light use efficiency of canola is only $0.615 \%-1.056 \%$ (Hamzei and Soltani 2012; Fochesatto et al., 2016). If the light use efficiency is increased by 0.1 percentage point, the yield can be increased by $20 \%-25 \%$ or more (Purcell et al., 2002; Soleymani 2017). However, it is generally accepted that crop yield is determined by biomass production and harvest index (Liao and Guan 2002; Singh et al., 2018; Danso et al., 2020). And biomass production of canola is the product of intercepted solar radiation by the canopy and light use efficiency (Zhang et al., 2013; Soleymani 2017). It is crucial to improve the light use efficiency for further improving canola yield due to beneficial biomass increase (Wang et al., 2011; Hamzei and Soltani 2012). Hence, it is one of the most effective ways to improve canola yield by improving light use efficiency.

It is reported that intercepted fraction of solar radiation depends on canopy morphological characteristics of canola plant (Hamzei and Soltani 2012; Kuai et al., 2016; Singh et al., 2018). Effects of plant type on the light receiving situation mainly were whether the intercepted solar light energy could be evenly distributed to all leaves (Wang et al., 2015; Fochesatto et al., 2016). The plant morphological characteristics included plant height, number of branches, length and angle, leaf size, shape, layer and position, petiole length and angle, etc. (Muller et al., 2005). Hence, plant morphology of efficient light receiving situation is the basis of high light efficiency of canola (Diepenbrock 2000; Momoh and Zhou 2001). However, the difficulty of high light efficiency breeding of canola was to determine effective physiological indicators and simple screening and identification technology
(Muller et al., 2006; Hamzei and Soltani 2012). Principal component analysis could integrate a linear combination of multiple indicators into fewer representative indicators. The representative indicators were not related to each other, but also could reflect the information of the original multiple indicators. It gradually applies to the comprehensive evaluation of crop stress.

In this research, sixty canola varieties with different solar light conditions were analyzed by correlation analysis, principal component analysis, membership function and cluster analysis. The weight of plant morphological indicator was analyzed to obtain the comprehensive evaluation value of light use efficiency. The purpose of this study was to provide a reference method for the selection of high LUE canola cultivars. At the same time, the results in this study could provide theoretical guidance for high LUE breeding and canola production in Southwest China.

\section{Materials and methods}

\subsection{Experimental materials}

This study was conducted at the potted experiment site of Tongren University during the 2017-2018 growing seasons. Sixty canola varieties were selected, which had been widely planted in the arable crop planting areas of the Yangtze River Basin. The sixty canola varieties were provided by the college of plant science and technology in Huazhong agricultural university and were numbered as No.(1)-(60). The experimental varieties were as follows: (1) BY517, (2) BYZ12, (3) CSY, (4) CYZ83, (5) CZY2, (6) CZY3, (7) DAZ600, (8) DD95, (9) DZY10, (10) DZY5, (11) FY668, (12) FY792, (13) FYZ520, (14) GJZY3, (15) GYZ6, (16) HXY12, (17) HZ13, (18) HZ62, (19) HZ9, (20) JHH, (21) JLY10, (22) JLY5, (23) JLY7, (24) JLYT, (25) JXY11, (26) KLY1, (27) LY9, (28) QDJ, (29) QY6, (30) QZ2, (31) QZ7, (32) RHY6, (33) SG127, (34) SXY9, (35) XDZY9, (36) XY1, (37) XY50, (38) XYZ108, (39) XZY814, (40) YB, (41) YBS, (42) YG2009, (43) YY10, (44) YY50, (45) YY57, (46) YY817, (47) YY9, (48) ZNY9, (49) ZS10, (50) ZS11, (51)ZS12, (52) ZS5, (53) ZS9, (54) ZY18, (55) ZY589, (56) ZYY8, (57) YZ11, (58) ZYZ19, (59) ZYZ28, (60) ZYZ781.

\subsection{Experimental design and crop management}

The pot experiment was a two-factor based on a completely randomized design. The main-factor was the two solar light intensity treatments, including (1) natural light supply (as control 
treatment);(2) shading treatment which was simulated by adding nylon net to reduce natural light by $20 \%$ (based on a series of preliminary experiments to evaluate canola growth in the light intensity by shading $20 \%$ natural light). Two treatment groups were set up in this experiment, and each group included 60 canola plants which represented the 60 experimental varieties: in group 1, canola plants were exposed to the sun directly (without shading), which was set as a control treatment group. In group 2, plants were covered with one layer of two stitches shading nylon net (with 20\% shading), which was shading treatment. The experiment consists of 8 groups, which included 4 shading groups and control groups, respectively. In the experiment, each pot was treated as one replicate and all the treatments were repeated by four times, so each cultivar was planted in eight pots. All the pots were fully randomized and were re-randomized once a week to minimize heterogeneity within each group.

In the pot experiment, locally collected arable field soil was used, and the soil nutrient conditions were as follows: alkali hydrolyzable nitrogen of $62.79 \mathrm{mg} \mathrm{kg}^{-1}$, available phosphorus of $10.82 \mathrm{mg} \mathrm{kg}^{-1}$ and available potassium of $94.13 \mathrm{mg} \mathrm{kg}^{-1}$. The canola varieties were grown in $30 \mathrm{~cm}$ diameter, freedraining plastic pots in an open field with $30 \mathrm{~cm}$ spacing between pots at the Tongren University, Guizhou $\left(109^{\circ} 13^{\prime} \mathrm{E}\right.$, $27^{\circ} 47^{\prime} \mathrm{N}, 490 \mathrm{~m}$ above sea level). Canola plants in each pot received $0.68 \mathrm{~g} \mathrm{~N}$ as urea, $0.26 \mathrm{~g} \mathrm{P}_{2} \mathrm{O}_{5}$ as superphosphate and $0.60 \mathrm{~g} \mathrm{~K}_{2} \mathrm{O}$ as potassium chloride. $\mathrm{N}$ fertilizers were split applied with $50 \%$ as basal, $50 \%$ at bolting.

The dosage of boron (B) was $2.4 \mathrm{mg} \mathrm{pot}^{-1}$, and $\mathrm{P}_{2} \mathrm{O}_{5}, \mathrm{~K}_{2} \mathrm{O}$ and $\mathrm{B}$ fertilizer were applied only once as basal. Pots were filled with nearly $12 \mathrm{~kg}$ of dried, sieved field soil. On 6 October 2017 , ten canola seeds of each cultivar were sown $5 \mathrm{~mm}$ deep in each pot and thinned to three uniform seedlings 10 days after emergence. Insects and diseases were controlled by chemicals, and weeds were controlled by hand removal.

\subsection{Sampling, data processing and analysis}

At maturity, each plant was separated into leaves, stem, senescent leaves, silique (walls) and seeds. Senescent leaves were collected each day and stored in paper bags for the irrespective plants. Seed yield per pot, seed yield on raceme and branches, and yield components (total branch number per pot, siliques per pot on raceme and branches, seed number per silique on raceme and branches were measured. Plant parts were dried in an air-forced oven at $70{ }^{\circ} \mathrm{C}$ for $72 \mathrm{~h}$ and weighed for dry matter weight. follows:

The formulas (1)-(4) used in the statistical analysis were as

High light use coefficient(HLC)

= shading treatment characteristic value/ control treatment characteristic value,

$$
U\left(X_{j}\right)=\left(X_{j}-X_{\text {min }}\right) /\left(X_{\max }-X_{\text {min }}\right) \quad j=1,2 \ldots \ldots n .
$$

The membership function value of each comprehensive index of each cultivar $U\left(X_{j}\right)$ is obtained by formula (2), in which $X_{j}$ represents the $j$-th comprehensive indicator, $X_{\min }$ represents the minimum value of $j$-th comprehensive indicator, and $X_{\max }$ represents the maximum value of $j$-th comprehensive indicator.

$$
W_{j}=P_{j} / \sum_{j=1}^{n} P_{j} \quad j=1,2 \ldots \ldots n .
$$

In the formula (3), $W_{j}$ represents the importance of the $j$-th comprehensive indicator in all comprehensive indicators; $P_{j}$ is the contribution rate of the $j$-th comprehensive indicator of each cultivar.

$$
D=\sum_{j=1}^{n}\left[U\left(X_{j}\right) \times W_{j}\right] \quad j=1,2 \ldots \ldots n .
$$

In the formula (4), $D$ value is the comprehensive evaluation value of light use efficiency of each genotype under the shading condition of natural solar radiation.

In this research, all data for the traits were collected from four replicates. An average of four replicates for every trait under two light conditions were calculated for each canola variety. SPSS 21 software was used for statistical analyses, principal component analysis, regression analysis and cluster analysis. The differences between the means were compared by Fisher's protected least significant difference test $(P<0.05)$.

\section{Results}

\subsection{High light use coefficient of various characters in canola}

In this experiment, the ratio of the character value to the corresponding value under shading treatment was defined as the high light use coefficient (HLC) of a character for the sixty varieties. The HLC of 12 characters tested in the experiment was quite different for 60 different genotypes by the result analysis of the HLC of each character (Tab. 1). The characters had different variation ranges for each genotype, and the greatest changes were observed in the pericarp dry weight and the dry weight of aboveground biomass, which were $-72.7 \%$ $646.3 \%$ and $-68.7 \%-143.3 \%$, respectively. On the contrary, minimal change occurred in plant height and root collar diameter, which were $-37.0 \%-15.3 \%$ and $-41.0 \%-27.0 \%$, respectively. However, if a single character was used to evaluate the HLC of canola, there would be one-sidedness to some extent.

Moreover, in the experiment, the correlation analysis data showed that (Tab. 2) there were different degrees of correlation between the HLC of each character. Because of this, the light use efficiency could not be accurately evaluated by these characters of different genotypes directly.

\subsection{Principal component analysis}

In the experiment, 12 single characters related to solar light use were chosen and measured to evaluate effects of characters of planting type on light use efficiency. Principal component analysis (Tab. 3) was subjected to the HLCs of the 12 characters. So the investigated 12 characters were transformed into four new independent representative indicators, representing $86.5 \%$ of the information of the 12 single characters. Analysis showed that the contributions of the screened 
R. Wang et al.: OCL 2020, 27, 43

Table 1. High light use coefficients of morphological traits of canola varieties.

\begin{tabular}{|c|c|c|c|c|c|c|c|c|c|c|c|c|}
\hline Variety & NPMS & NPPP & NSPP & OSW & PDWP & $\mathrm{PH}$ & RSRW & RT & SWMR & SYPP & ShDW & StDW \\
\hline BYZ12 & 1.07 & 1.06 & 0.82 & 1.19 & 1.14 & 0.81 & 0.61 & 0.90 & 0.65 & 0.70 & 0.84 & 0.74 \\
\hline CYZ83 & 0.72 & 1.22 & 0.95 & 0.94 & 0.75 & 0.92 & 1.27 & 0.93 & 0.53 & 0.95 & 0.89 & 0.95 \\
\hline CZY2 & 0.64 & 0.63 & 0.85 & 0.89 & 0.43 & 0.78 & 0.96 & 0.75 & 0.41 & 0.42 & 0.46 & 0.54 \\
\hline DD95 & 0.60 & 0.64 & 0.75 & 1.38 & 0.51 & 0.81 & 0.86 & 0.82 & 0.35 & 0.43 & 0.51 & 0.60 \\
\hline DZY10 & 0.84 & 1.04 & 0.92 & 1.10 & 0.92 & 0.79 & 0.98 & 0.87 & 0.76 & 0.91 & 0.84 & 0.71 \\
\hline DZY5 & 0.66 & 0.62 & 0.75 & 1.16 & 0.83 & 0.77 & 0.99 & 0.59 & 0.83 & 0.83 & 0.74 & 0.57 \\
\hline FY668 & 0.75 & 1.15 & 1.11 & 0.80 & 0.57 & 0.82 & 1.13 & 0.79 & 0.46 & 0.64 & 0.60 & 0.58 \\
\hline FY792 & 1.06 & 1.48 & 0.84 & 0.94 & 1.06 & 0.91 & 1.07 & 0.95 & 0.76 & 1.13 & 1.08 & 1.06 \\
\hline HZ13 & 0.64 & 0.70 & 1.06 & 0.79 & 0.47 & 0.79 & 1.10 & 0.69 & 0.30 & 0.53 & 0.53 & 0.57 \\
\hline HZ62 & 0.79 & 0.70 & 0.98 & 0.82 & 0.50 & 0.85 & 1.05 & 0.69 & 0.49 & 0.52 & 0.51 & 0.52 \\
\hline HZ9 & 0.60 & 0.64 & 1.01 & 0.95 & 0.51 & 0.71 & 1.00 & 0.69 & 0.41 & 0.51 & 0.51 & 0.52 \\
\hline JHH & 0.52 & 0.89 & 0.78 & 0.87 & 0.77 & 0.70 & 0.39 & 0.99 & 0.10 & 0.30 & 0.52 & 0.53 \\
\hline JLY10 & 1.02 & 1.15 & 0.85 & 1.18 & 0.92 & 0.95 & 1.06 & 0.96 & 0.55 & 0.98 & 0.96 & 0.98 \\
\hline JLY5 & 0.96 & 1.10 & 0.77 & 1.12 & 0.81 & 0.97 & 1.04 & 0.89 & 0.73 & 0.85 & 0.86 & 0.92 \\
\hline JLY7 & 0.70 & 0.87 & 0.62 & 1.26 & 0.61 & 0.83 & 0.92 & 0.87 & 0.44 & 0.56 & 0.59 & 0.61 \\
\hline JLYT & 1.02 & 1.14 & 0.73 & 1.10 & 0.99 & 0.93 & 1.04 & 0.93 & 0.77 & 1.02 & 1.01 & 1.02 \\
\hline JXY11 & 0.80 & 1.21 & 0.90 & 0.94 & 0.90 & 0.97 & 0.93 & 0.92 & 0.41 & 0.84 & 0.97 & 1.16 \\
\hline KLY1 & 0.92 & 1.41 & 0.70 & 0.86 & 0.96 & 0.96 & 1.24 & 0.82 & 0.70 & 1.20 & 1.12 & 1.17 \\
\hline SXY9 & 0.68 & 0.73 & 0.89 & 1.14 & 0.55 & 0.83 & 0.81 & 0.75 & 0.45 & 0.45 & 0.54 & 0.63 \\
\hline XDZY9 & 0.71 & 0.93 & 0.93 & 1.15 & 0.89 & 0.79 & 1.03 & 0.90 & 0.47 & 0.92 & 0.84 & 0.74 \\
\hline XY1 & 0.67 & 1.36 & 0.74 & 1.01 & 0.90 & 0.87 & 0.80 & 1.06 & 0.29 & 0.73 & 0.95 & 1.22 \\
\hline XY50 & 0.91 & 1.19 & 0.85 & 0.93 & 0.78 & 0.95 & 1.07 & 0.94 & 0.49 & 0.84 & 0.86 & 0.95 \\
\hline XYZ108 & 0.69 & 1.25 & 0.88 & 1.00 & 0.85 & 0.93 & 0.74 & 1.13 & 0.43 & 0.63 & 0.91 & 1.26 \\
\hline XZY814 & 0.59 & 1.27 & 0.93 & 0.87 & 0.93 & 1.10 & 0.83 & 1.09 & 0.31 & 0.77 & 0.95 & 1.14 \\
\hline YB & 0.52 & 0.44 & 0.92 & 1.34 & 7.46 & 0.65 & 0.05 & 0.64 & 0.32 & 0.38 & 2.43 & 0.39 \\
\hline YBS & 1.00 & 1.05 & 1.00 & 1.16 & 0.61 & 0.96 & 1.15 & 0.90 & 0.61 & 0.70 & 0.65 & 0.65 \\
\hline YG2009 & 0.91 & 1.12 & 0.90 & 1.08 & 1.08 & 1.00 & 0.89 & 1.00 & 0.70 & 0.96 & 1.03 & 1.07 \\
\hline YY10 & 0.97 & 1.61 & 0.78 & 0.95 & 1.10 & 0.93 & 0.81 & 1.00 & 0.57 & 0.89 & 0.97 & 0.94 \\
\hline YY50 & 0.82 & 1.02 & 0.81 & 1.06 & 1.02 & 0.95 & 0.91 & 1.05 & 0.55 & 0.92 & 1.00 & 1.06 \\
\hline YY57 & 0.54 & 1.36 & 0.77 & 0.79 & 1.07 & 0.95 & 0.73 & 0.98 & 0.22 & 0.78 & 0.93 & 0.96 \\
\hline YY817 & 0.82 & 1.65 & 1.02 & 0.96 & 1.17 & 1.04 & 0.80 & 1.05 & 0.58 & 0.94 & 1.06 & 1.08 \\
\hline YY9 & 0.73 & 0.93 & 0.75 & 0.96 & 0.58 & 0.84 & 0.85 & 0.77 & 0.32 & 0.49 & 0.54 & 0.57 \\
\hline ZNY9 & 1.09 & 1.51 & 0.29 & 0.93 & 1.13 & 1.10 & 0.78 & 1.27 & 0.61 & 0.87 & 1.12 & 1.37 \\
\hline ZS10 & 0.84 & 0.77 & 0.88 & 1.09 & 0.64 & 0.81 & 0.97 & 0.77 & 0.65 & 0.62 & 0.59 & 0.51 \\
\hline ZS11 & 1.11 & 1.15 & 1.06 & 1.00 & 0.98 & 1.05 & 1.00 & 0.98 & 0.93 & 0.89 & 1.01 & 0.98 \\
\hline ZS12 & 1.17 & 1.51 & 0.89 & 0.84 & 1.21 & 1.02 & 0.78 & 1.01 & 0.77 & 0.94 & 1.11 & 1.20 \\
\hline ZS5 & 0.60 & 0.59 & 0.76 & 0.89 & 0.39 & 0.78 & 0.99 & 0.65 & 0.34 & 0.39 & 0.39 & 0.39 \\
\hline
\end{tabular}


Table 1. (continued).

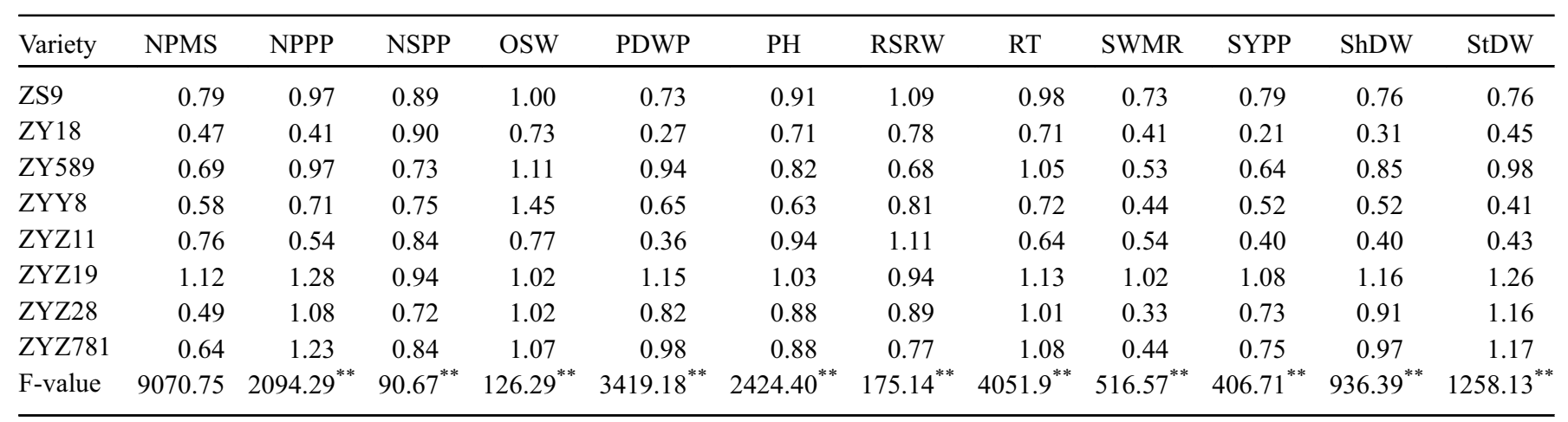

*Significant at 0.05 level; ${ }^{* *}$ significant at 0.01 level. PH: plant height; RT: rhizome thickness; NPMS: number of pods per main stem; NPPP: number of pods per plant; ShDW: shoot dry weight per plant; StDW: stem dry weight per plant; SYPP: seed yield per plant; SWMR: seed weight of main raceme pods per plant; NSPP: number seeds per pod; OSW: 1000-seed weight; PDWP: pericarp dry weight per plant; RSRW: ratio of seed dry weight to pericarp dry weight per plant. The same as below.

Table 2. Correlation matrix of light use coefficients for different characters.

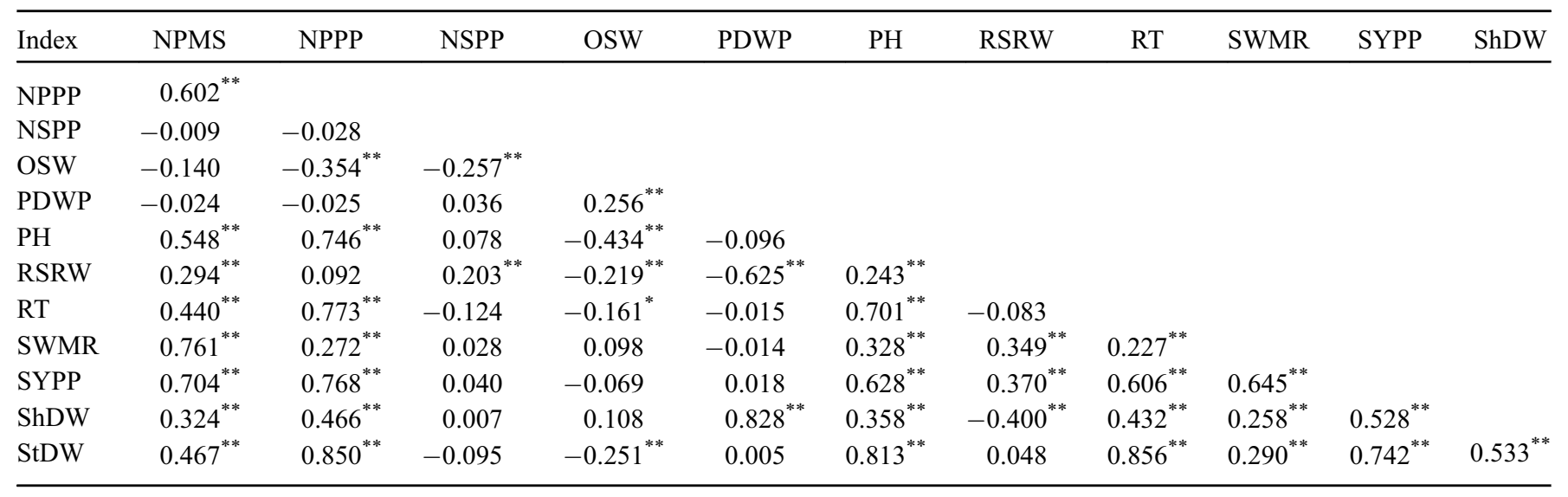

${ }^{*}$ Significant at 0.05 level; ${ }^{* *}$ significant at 0.01 level.

Table 3. Coefficients of comprehensive index and their contribution rate (CR).

\begin{tabular}{lrrrrrrrrrrrrr}
\hline Factor & NPMS & NPPP & NSPP & OSW & PDWP & PH & RSRW & RT & SWMR & SYPP & ShDW & StDW & CR(\%) \\
\hline CI1 & -0.3079 & -0.3732 & 0.0016 & 0.0891 & -0.0882 & -0.3449 & -0.0328 & -0.3393 & -0.2297 & -0.3741 & -0.2985 & -0.3801 & 42.50 \\
CI2 & 0.1550 & 0.0985 & 0.0787 & -0.2547 & -0.5400 & 0.1762 & 0.4728 & 0.0368 & 0.1266 & 0.1080 & -0.3977 & 0.0522 & 22.60 \\
CI3 & 0.3418 & -0.2114 & 0.0186 & 0.4399 & 0.0857 & -0.2045 & 0.2682 & -0.2688 & 0.5851 & 0.2194 & 0.0512 & -0.2351 & 11.80 \\
CI4 & 0.0045 & 0.0541 & -0.8093 & 0.4037 & -0.2163 & -0.0619 & -0.1376 & 0.2387 & -0.0019 & 0.0063 & -0.1306 & 0.1379 & 9.50 \\
\hline
\end{tabular}

four indicators were $42.5 \%, 22.6 \%, 11.8 \%$ and $9.5 \%$ respectively, and their cumulative contribution reached $86.5 \%$. Four indicators, the number of pods per plant, grain weight per plant, plant height and stem dry weight per plant, determined the first principal component, which could be roughly summarized as quantitative control characteristic factors and biomass characteristic factors. And the second principal component was determined by the pericarp weight per plant, the seed and pericarp weight ratio per plant, and the dry weight of the aboveground biomass per plant, which could be basically summarized as biomass and pod characteristic factors. Moreover, the 3rd and 4th principal components were determined by the seed weight of main inflorescence, seed number per pod, 1000-seed weight, root diameter and pod number of main inflorescence, which could be summarized to the biomass and quantity control factors.

\subsection{Comprehensive evaluation and cluster analysis of HLC of canola}

The formula (2) was used to calculate the membership function value of all representative characters of each variety, and the formula (3) to calculate the weight of four representative indicators. And the comprehensive evaluation 
R. Wang et al.: OCL 2020, 27, 43

Table 4. The value of comprehensive index (CI), index weight (IW), $U(X), D$ and prediction $(P)$ of each variety.

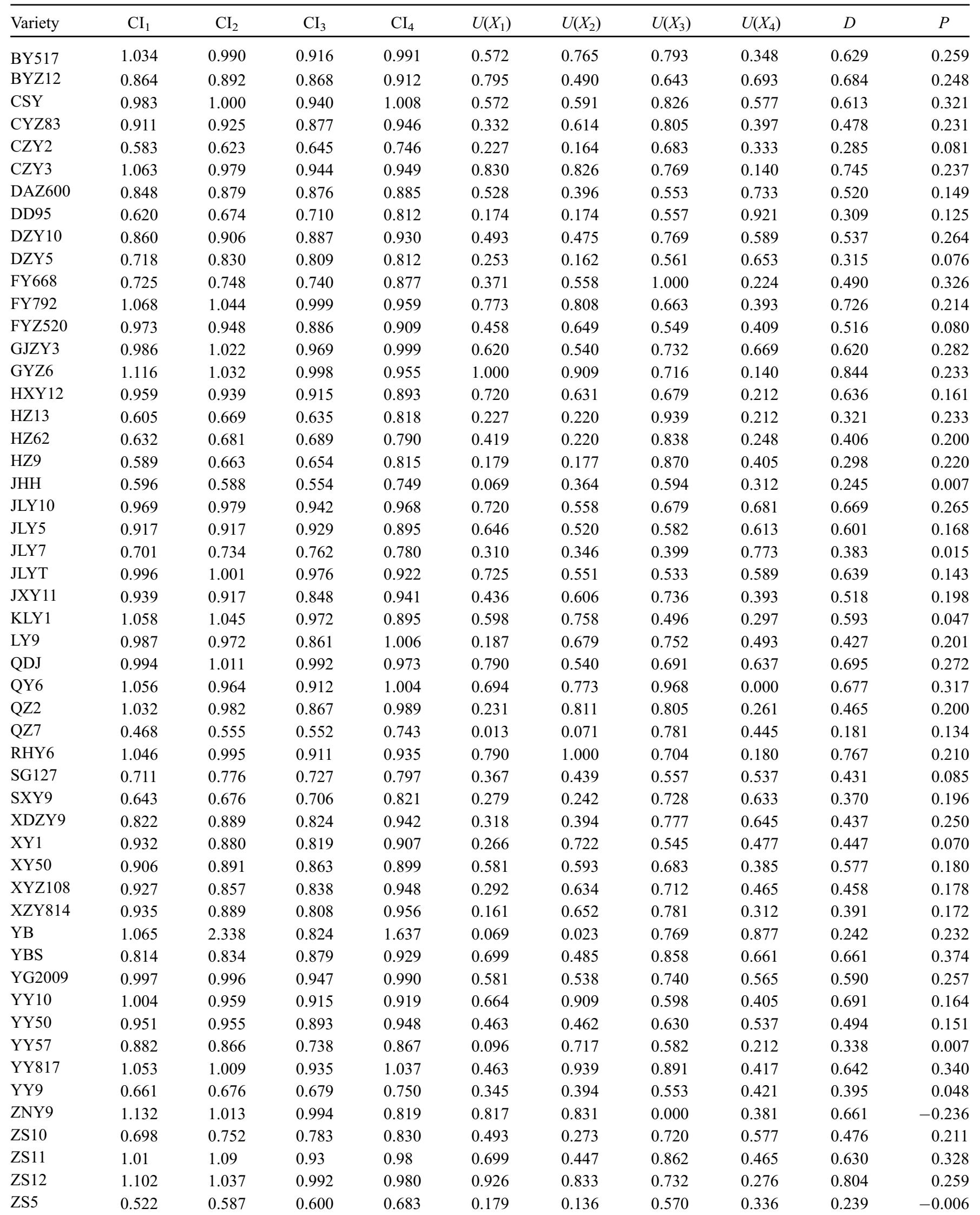


Table 4. (continued).

\begin{tabular}{lcccccccccc}
\hline Variety & $\mathrm{CI}_{1}$ & $\mathrm{CI}_{2}$ & $\mathrm{CI}_{3}$ & $\mathrm{CI}_{4}$ & $U\left(X_{1}\right)$ & $U\left(X_{2}\right)$ & $U\left(X_{3}\right)$ & $U\left(X_{4}\right)$ & $D$ \\
\hline ZS9 & 0.839 & 0.854 & 0.870 & 0.895 & 0.419 & 0.424 & 0.728 & 0.465 & 0.468 & 0.192 \\
ZY18 & 0.452 & 0.478 & 0.529 & 0.675 & 0.000 & 0.000 & 0.740 & 0.144 & 0.117 & 0.029 \\
ZY589 & 0.843 & 0.837 & 0.814 & 0.880 & 0.292 & 0.422 & 0.529 & 0.601 & 0.393 & 0.068 \\
ZYY8 & 0.595 & 0.692 & 0.710 & 0.811 & 0.148 & 0.230 & 0.561 & 1.001 & 0.320 & 0.147 \\
ZYZ11 & 0.566 & 0.620 & 0.659 & 0.700 & 0.384 & 0.096 & 0.671 & 0.185 & 0.326 \\
ZYZ19 & 1.139 & 1.091 & 1.084 & 1.048 & 0.856 & 0.659 & 0.793 & 0.489 & 0.756 \\
ZYZ28 & 0.863 & 0.850 & 0.784 & 0.882 & 0.026 & 0.505 & 0.525 & 0.493 & 0.271 \\
ZYZ781 & 0.931 & 0.903 & 0.847 & 0.955 & 0.227 & 0.624 & 0.663 & 0.553 & 0.427 & 0.006 \\
IW & & & & & 0.492 & 0.262 & 0.137 & 0.110 & \\
\hline
\end{tabular}

( $D$-value) of the high light efficiency was obtained by the formula (4) according to the $U$-value and weight of each representative index for each variety (Tab. 4). Furthermore, the $D$-value was regarded as the standard to evaluate the HLC of any variety. The $D$-values of GYZ6, ZS12, RHY6 and ZYZ19 were $0.844,0.804,0.767$ and 0.756 , respectively, which were relatively higher than others among the sixty varieties. And these four varieties had be screened and reached higher light use efficiency during the growing season in this study.

In order to comprehensively evaluate the light use efficiency of each variety, the 60 varieties could be divided into three categories with the $D$-value clustering method by the Euclidean distance (Fig. 1). And the first category with higher light use efficiency were ZS12, GYZ6, FY792, RHY6, CZY3 and ZYZ19 among the sixty varieties; the second with medium light use efficiency included 18 varieties such as YY817, HXY12, ZNY9, ZYZ28, ZY18 and QZ7; and the rest 36 varieties, such as LY9, ZYZ781, SG127, XDZY9, XY1, YY50 and so on, belonged to the third category with low light use efficiency relatively.

\subsection{Screening of indicators for identifying light use efficiency for canola}

The canola genotypes with high light use efficiency were identified and evaluated by means of the established mathematical model, which could predict light use efficiency and run stepwise regression analysis on 12 investigated single indicators for all varieties. The optimal regression equation was established by taking the comprehensive evaluation value of high light use efficiency ( $D$-value) as the dependent variable and the HLC of each single indicator as the independent variable: $D=-0.513$ $+0.645 X_{1}+0.2 X_{2}+0.169 X_{3}+0.135 X_{4} \quad\left(F=57201.07^{* *}\right.$, $\left.R^{2}=0.9999\right)$, in this formula, $X_{1}, X_{2}, X_{3}$ and $X_{4}$ representing the stem dry weight per plant, pod number per plant, seed number per pod and 1000-seed weight, respectively.

It could be seen from the equation that among the 12 single indicators, the above four indicators had a significant impact on the light use efficiency. Therefore, these indicators could be selected to simplify the identification of light use efficiency for deferent canola varieties. The predictive value ( $P$-value) significantly correlated the comprehensive evaluation value of high light use efficiency ( $D$-value) of the 60 varieties $\left(r=0.8399^{* *}\right)$, and these results showed that the equation could effectively and accurately predict the high light use efficiency of canola varieties.

\section{Discussion}

\subsection{Evaluating the high light use efficiency of canola varieties}

How to make full use of solar radiation of the earth's surface for photosynthesis has been a fundamental problem for agricultural production (Diepenbrock 2000; Muller et al., 2006). As the light use of crops was a comprehensive process, the canola variety with high light use efficiency was such a morphologic complexity of plant type which had the common characteristics of the high light interception, high photosynthetic capacity and high photosynthetic products distribution to economic organs (Fortescue and Turner 2007; Muller et al., 2008; Zajac et al., 2011). The light use efficiency evaluation of canola was the process of selecting, evaluating and classifying the photosynthetic efficiency for different varieties by selecting appropriate identification indicators and evaluating methods.

The light use efficiency was affected by many factors, such as the gene, phenotype, environmental factors, and so on (Brunel-Muguet et al., 2013; Wang et al., 2015; Singh et al., 2018). As previous papers concluded, the plant canopy composed of leaves, stems, branches and pods was the main place for photosynthesis in canola, and also was the intersection of "source and reservoir" to yield formation (Diepenbrock 2000; Momoh and Zhou 2001; Hamzei and Soltani 2012; Shabani et al., 2014; Fochesatto et al., 2016). Owing to the influence of plant height, angle and orientation between leaves, branches, pods and main stem, length of leaves and branches and other factors, the photosynthetic area coefficient and light distribution in plant canopy were very different, resulting in the different photosynthetic efficiency of the canopy consequently (Han et al., 2014; Cui et al., 2015; Chang et al., 2016). The response of a single plant indicator to light use efficiency was different for different varieties, and might be difficult to reflect the light use efficiency comprehensively and accurately with a single indicator (Denoroy et al., 2002; Brodrick et al., 2013; Mattera et al., 2013; Fochesatto et al., 2016). Therefore, it was more comprehensive and reliable to evaluate the light use efficiency of crops with multiple indicators. In recent years, principal 
R. Wang et al:: OCL 2020, 27, 43

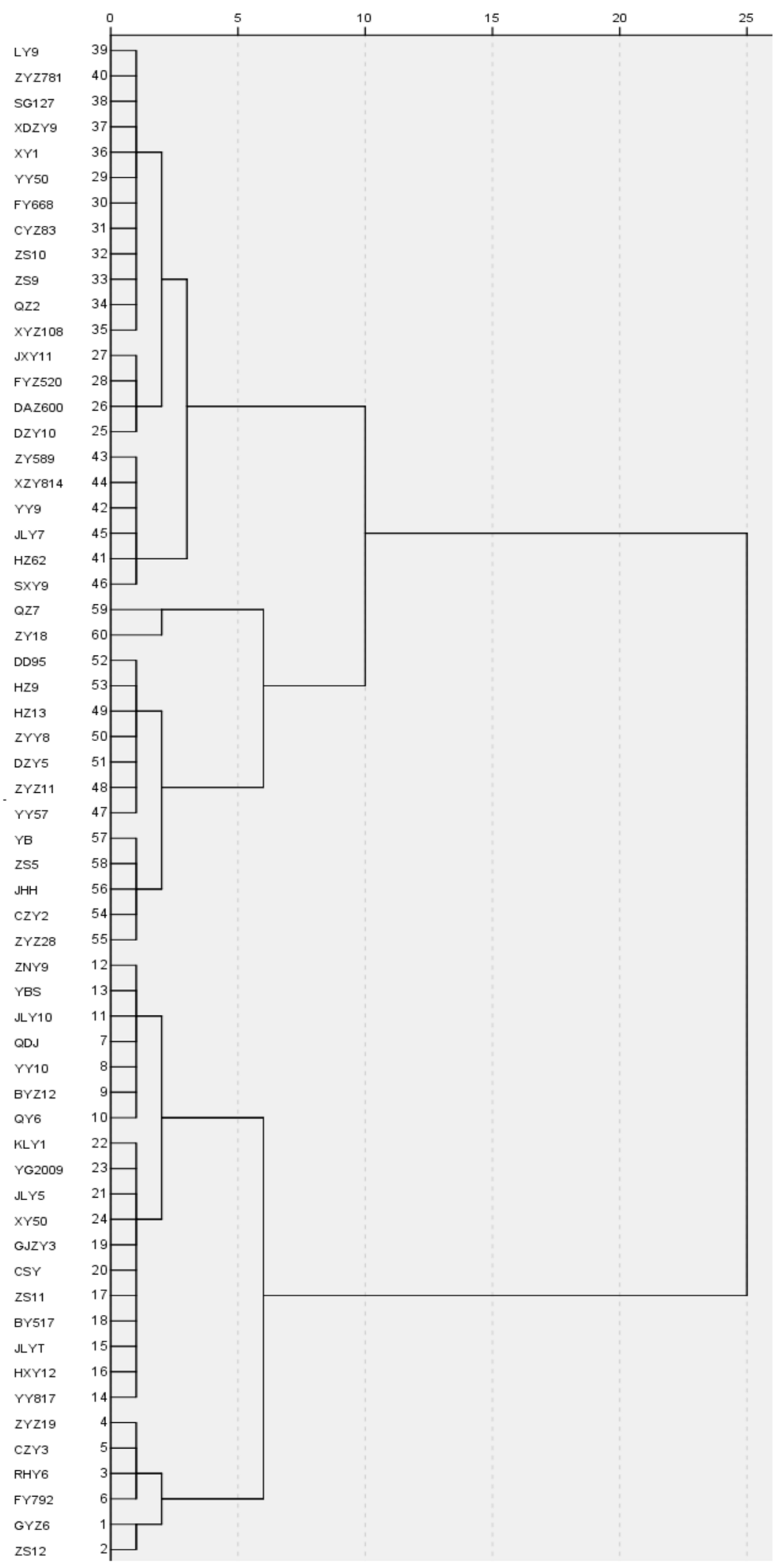

Rescaled distance cluster combine

Fig. 1. Dendrogram based on $D$-value by cluster analysis. 
component analysis and membership function method had been applied to identifying the specific traits of other crops (Zhu et al., 2020), but there were few reports in the high light use efficiency of canola. In this study, the HLC of each character was used as an indicator to measure the light use efficiency of canola plant. Using principal component analysis, the 12 single indicators were integrated into four new and independent representative indicators. These four representative indicators could not only contain the information of the original primary indicators in many aspects, but also include the information of each original indicator with little obvious difference. Although the light use efficiency of the 60 canola varieties was determined by all these four indicators, the light use efficiency of a variety could not be completely determined by one of the four representative indicators. The corresponding membership function values were calculated by the contribution share of four representative index values, and weighted according to the relative importance of each representative index, and obtained the comprehensive evaluation values $(D$ values) of light use efficiency for the sixty varieties. Because the $D$-value was a dimensionless pure number, it was compared with the differences of light use efficiency among varieties. In this research, the sixty varieties were divided into three categories through cluster analysis: such six varieties as ZS12, GYZ6, FY792, RHY6, CZY3 and ZYZ19 could present the higher light use efficiency; and such 36 varieties as LY9, ZYZ781, SG127, XDZY9, XY1, YY50 and so on presented the lower ones; the remaining eighteen varieties were between the above both.

\subsection{Evaluating the index of high HLC of canola}

In the evaluation, identification and selection of high light use efficiency varieties resources, it was particularly important to determine the simple and effective evaluation indicators ( $\mathrm{Li}$ et al., 2015; Jian et al., 2016; Channaoui et al., 2019). To the present, some scholars had studied and put forward many morphological and physiological indicators related to high light use efficiency of crops (Earl and Davis 2003; Brodrick et al., 2013; Fochesatto et al., 2016; Singh et al., 2018; Danso et al., 2020). By contrast, in this study, the evaluating mathematical model of light use efficiency was established to screen the identification indicators of high light use efficiency during the whole growth season, and to analyze the relationship between light use efficiency and the indicators of high light use efficiency. The $D$-value was used as the dependent variable and the high HLC of each character as the independent variable through the stepwise regression analysis. The results showed that the light use efficiency could be influenced by the stem dry weight per plant, the pod number per plant, the seed number per pod and the 1000-seed weight. In other words, these four indicators could be regarded as the identification indicators of light use efficiency during the whole growth period of canola.

The light use efficiency of crops was not only affected by the crop growth and development stage, but also by the specific physiological and biochemical process (Fochesatto et al., 2016; Gauthier et al., 2017). In the future research, we should further explore and improve the comprehensive evaluation method of high light efficiency of canola in combination with the simple and easy to measure physiological characteristics.

\section{Conclusion}

Based on the comprehensive analysis of the HLC of the 12 characters during the growing season for the sixty canola varieties, all characters might be correlated and be transformed into the four independent representative indicators. Thus, the comprehensive evaluation value ( $D$-value) was calculated to estimate the light use efficiency of these 60 varieties. With the cluster analysis of $D$-value, the 60 varieties were divided into three categories: the 36 varieties with the lower light use efficiency, the 18 varieties with the medium efficiency, and the remaining six varieties with the higher light use efficiency.

Through stepwise regression analysis, four indicators of high light use efficiency had been selected, such as the stem dry weight per plant, the number of pods per plant, the number of seeds per pod and the weight of 1000 seeds. And the optimal regression equation was established, which could predict the characteristics of light use efficiency of canola faster and conveniently. Accordingly, the method of principal component analysis, cluster analysis and stepwise regression analysis might be more reliable to evaluating canola light use efficiency comprehensive, which not only ingeniously avoided the one sidedness and instability of a single indicator, but also revealed the relationship between the high light use efficiency and the characters related to light use for canola.

Acknowledgements. Funding for this research was provided by National Natural Science Foundation of China (31660354), the Program for Top Talents in Science and Technology of Education Department in Guizhou (KY [2016]108) and Doctors' Initial Funding Project of Tongren University (trxyDH1608).

Conflicts of interest. The authors declare that they have no conflicts of interest in relation to this article.

\section{References}

Brodrick RM, Bange P, Milroy SP, Hammer GL. 2013. Physiological determinants of high yielding ultra-narrow row cotton: Canopy development and radiation use efficiency. Field Crops Res 148: 86-94.

Brunel-Muguet S, Beauclair P, Bataille MP, et al. 2013. Light restriction delays leaf senescence in winter oilseed rape (Brassica napus L.). J Plant Growth Regul 32: 506-518.

Chang SX, Li CX, Yao XY, et al. 2016. Morphological, photosynthetic, and physiological responses of rapeseed leaf to different combinations of red and blue lights at the rosette stage. Front Plant Sci 7: 1144.

Channaoui S, El Idrissi IS, Mazouz H, Nabloussi A. 2019. Reaction of some rapeseed (Brassica napus L.) genotypes to different drought stress levels during germination and seedling growth stages. OCL 26.

Cui L, Su B, Yang F, Yang W. 2015. Study on relationship between light interception and light use of soybean canopy in relay strip intercropping system. Sci Agric Sin 48: 43-54.

Danso EO, Yakubu A, Arthur E, Sabi EB, Abenney-Mickson S, Andersen MN. 2020. Effect of rice straw biochar and irrigation on growth, dry matter yield and radiation-use efficiency of maize grown on an Acrisol in Ghana. J Agron Crop Sci 206: 296-307. 
Denoroy P, Thiebeau P, Gosse G. 2002. A method for assessing intercepted radiation by a crop with a low leaf area: An application to oilseed rape. $O C L$ 9: 54-63.

Diepenbrock W. 2000. Yield analysis of winter oilseed rape (Brassica napus L.): A review. Field Crops Res 67: 35-49.

Earl HJ, Davis RF. 2003. Effect of drought stress on leaf and whole canopy radiation use efficiency and yield of maize. Agron $J$ 95: 688-696.

Fochesatto E, Nied AH, Bergamaschi H, et al. 2016. Interception of solar radiation by the productive structures of spring canola hybrids. Cienc Rural 46: 1790-1796.

Fortescue JA, Turner DW. 2007. Changes in seed size and oil accumulation in Brassica napus L. by manipulating the sourcesink ratio and excluding light from the developing siliques. Aust $J$ Agric Res 58: 413-424.

Gauthier M, Pellet D, Monney C, Herrera JM, Rougier M, Baux A. 2017. Fatty acids composition of oilseed rape genotypes as affected by solar radiation and temperature. Field Crops Res 212: $165-174$.

Hamzei J, Soltani J. 2012. Deficit irrigation of rapeseed for watersaving: Effects on biomass accumulation, light interception and radiation use efficiency under different $\mathrm{N}$ rates. Agric Ecosyst Environ 155: 153-160.

Han YY, Wang GY, Zhou XB, Chen YH, Liu P. 2014. Radiation use efficiency and yield response of winter wheat to planting patterns and irrigation in Northern China. Agron J 106: 168-174.

Jian HJ, Wang J, Wang TY, Wei LJ, Li J, Liu LZ. 2016. Identification of rapeseed microRNAs involved in early stage seed germination under salt and drought stresses. Front Plant Sci 7: 658.

Kuai J, Sun YY, Zhou M, et al. 2016. The effect of nitrogen application and planting density on the radiation use efficiency and the stem lignin metabolism in rapeseed (Brassica napus L.). Field Crops Res 199: 89-98.

Li L, Li JG, Shen MC, Zhang CL, Dong YH. 2015. Cold plasma treatment enhances oilseed rape seed germination under drought stress. Sci Rep 5: 130033

Liao G, Guan C. 2002. Study on Characteristics of dry matter accumulation, distribution and transfer of winter rapeseed (Brassica napus). Acta Agron Sin 28: 52-58.

Mattera J, Romero LA, Cuatrin AL, Cornaglia PS, Grimoldi AA. 2013. Yield components, light interception and radiation use efficiency of lucerne (Medicago sativa L.) in response to row spacing. Eur J Agron 45: 87-95.

Momoh EJJ, Zhou W. 2001. Growth and yield responses to plant density and stage of transplanting in winter oilseed rape (Brassica napus L.). J Agron Crop Sci 186: 253-259.

Muller J, Behrens T, Diepenbrock W. 2005. Measurement and modelling of canopy gas exchange of oilseed rape. Agric For Meteorol 132: 181-200.
Muller J, Behrens T, Diepenbrock W. 2006. Use of a new sigmoid growth equation to estimate organ area indices from canopy area index in winter oilseed rape (Brassica napus L.). Field Crops Res 96: 279-295.

Muller K, Bottcher U, Meyer-Schatz F, Kage H. 2008. Analysis of vegetation indices derived from hyperspectral reflection measurements for estimating crop canopy parameters of oilseed rape (Brassica napus L.). Biosyst Eng 101: 172-182.

Purcell LC, Ball RA, Reaper JD, Vories ED. 2002. Radiation use efficiency and biomass production in soybean at different plant population densities. Crop Sci 42: 172-177.

Shabani A, Sepaskhah AR, Kamgar-Haghighi AA. 2014. Estimation of yield and dry matter of rapeseed using logistic model under water salinity and deficit irrigation. Arch Agron Soil Sci 60: 951-969.

Singh J, Singh SP, Kingra PK. 2018. Influence of sowing time and planting geometry on yield and radiation use efficiency of various rapeseed-mustard cultivars. J Agrometeorol 20: 246-248.

Soleymani A. 2017. Light response of sunflower and canola as affected by plant density, plant genotype and $\mathrm{N}$ fertilization. J Photochem Photobiol B-Biol 173: 580-588.

Velicka R, Marcinkeviciene A, Kosteckas R, Pupaliene R, Duchovskis P, Brazaityte A. 2012. The influence of crop density on the photosynthetic characteristics and productivity of the spring oilseed rape under non-fertilized and fertilized conditions. J Food Agric Environ 10: 850-856.

Wang R, Cheng T, Hu LY. 2015. Effect of wide-narrow row arrangement and plant density on yield and radiation use efficiency of mechanized direct-seeded canola in Central China. Field Crops Res 172: 42-52.

Wang Y, Lu J, Li X. et al. 2011. Study on nitrogen fertilizer effect and optimum fertilizer rate for transplanting and direct-seeding rapeseed. Sci Agric Sin 44: 4406-4414.

$\mathrm{Xu} \mathrm{ZH}$, Luo T, Rao N. et al. 2019. High yield achieved by earlymaturing rapeseed with high light energy and temperature production efficiencies under ideal planting density. Crop Sci 59: 351-362.

Zajac T, Oleksy A, Stoklosa A, Klimek-Kopyra A. 2011. Comparison of morphological traits, productivity and canopy architecture of winter oilseed rape (Brassica napus L.) and white mustard (Sinapis alba L.). J Appl Bot Food Qual-Angewandte Botanik 84: 183-191.

Zhang HP, Berger JD, Milroy SP. 2013. Genotype $\times$ environment interaction studies highlight the role of phenology in specific adaptation of canola (Brassica napus L.) to contrasting Mediterranean climates. Field Crops Res 144: 77-88.

Zhu TT, Li J, Liu YY, Tong XJ, Yu Q. 2020. Leaf photosynthetic light response of summer maize: comparison of models and analysis of parameters. Photosynthetica 58: 19-28.

Cite this article as: Wang R, Peng W, Hu L, Wu W. 2020. Study on screening of canola varieties with high light use efficiency and evaluation of selecting indices. $O C L$ 27: 43 . 